\title{
EMSP FINAL REPORT
}

$\begin{array}{ll}\text { Project Title: } & \text { Multi-Regional Reactive Transport Due to Strong Anisotropy in } \\ \text { Unsaturated Soils with Evolving Scales of Heterogeneity }\end{array}$

Covering Period: October, 2002 - September, 2006

Date of Report: October 13, 2006

Recipient: $\quad$ Lehigh University/Villanova University

Center for Engineering and Education Research

800 Lancaster Avenue Villanova Pa 19085

Award Number: DE-FG07-02ER63512

Contact(s): $\quad$ Horace Keith Moo-Young, Principal Investigator name, 610-519-7440, h.keith.moo.young@villanova.edu

Project Objective: Anisotropic and heterogeneous flow in unsaturated porous media is dependent on saturation conditions, and currently there exist limited options that adequately model this phenomenon. The phenomenon of lateral spreading commonly attributed to anisotropy can move contaminants beyond compliance boundaries at unexpected velocities essentially bypassing large regions of the subsurface. Modified UFA and scaled centrifuge tests in conjunction with numerical simulations of the system are used to investigate variations in unsaturated hydraulic conductivity and as to how it relates to transport in soil, and Richards equation which is derived for use in a centrifugal field. The modified UFA method is based on steady state flow in unsaturated soil, and is used in determination of the unsaturated hydraulic conductivities for a layered system comprised of soils with different hydraulic conductivities. The centrifuge modeling conducted under elevated levels of gravitational acceleration is useful in reducing the model size and test time resulting in a feasible means of study in laboratory conditions and time frames.

Background: At Hanford, a good example of the limitations of current conceptualizations is in the prediction of field-scale transport in the vadose zone of tank farms and other waste-management facilities. Contaminant plumes in Hanford's vadose zone typically show extensive lateral spreading with splitting along flow paths and multiple zones of highcontaminant concentrations, even in sediments that appear homogeneous and isotropic at the regional scale. At one site, contact between the coarse-grained and fine-grained facies of the Upper Hanford Formation occurs at a depth of $55 \mathrm{ft}(16.8 \mathrm{~m})$ and the fine-grained sediments appear to play a major role in transport. Much of the ${ }^{238} \mathrm{U}$, (the most mobile of the detected radionuclides), ${ }^{60} \mathrm{Co},{ }^{125} \mathrm{Sb}$, and ${ }^{154} \mathrm{Eu}$ contamination is in the eastern region and appears to have emanated from tanks BX-101 and BX-102 (DOE-GJPO, 1998). Thus, contaminants appear to have migrated laterally more than $100 \mathrm{ft}(30.5 \mathrm{~m})$ within the fine-grained sediments. 
Investigation of the 1973 leak from the single-shelled tank 241-T-106 also showed significant lateral fluid movement and isopleths of ${ }^{106} \mathrm{Ru}$ suggested a ratio of lateral to vertical spreading in excess of 4:1 (Rouston et al., 1979). However, this aspect of flow and transport has proven quite difficult to predict at the Hanford Site with current conceptual models and attempts to describe similar distributions within Tank Farms have had limited success even with finely discretized domains (Ward et al. 1997; White et al. 2001). Discrepancies between measured and predicted subsurface distributions of moisture and solutes have been observed in wellcontrolled, intermediate-scale field simulations of a subsurface leak. Under Hanford's Groundwater/Vadose Zone Integration Project, a series of field experiments were recently conducted to study the behavior of subsurface tank leaks (Gee and Ward, 2001). A numerical simulation of one of several water injections treated the site as a heterogeneous system with parameters conditioned on initial water-content distributions. The domain was discretized into more than 20,000 cells, and each cell was assigned a unique set of hydraulic parameters; i.e., each cell represented a different soil. These simulations did a reasonably good job of describing the general features of the plume but were unable to adequately describe the lateral spreading. Given the fine discretization of the model, the solution of the problem does not appear to lie in finer discretizations or computers that are more powerful. What is needed is a better conceptual description of lateral conductivity at or near interfaces to reflect the observed anisotropy.

\section{Status: $\quad$ COMPLETE}

\section{EXPERIMENTAL SETUP}

The experimental setup used in the first phase of this study consisted of a $6 \times 6 \times 6$ inch modeling box with removable transparent faceplates. There were two drainage faces with dipped surfaces similar to the ones used in the UFA method for both the horizontal and vertical drainage. One face of the modeling box had ports for up to 15 TDR probes. For this particular study, the probes were set up such that there were 3 TDR probes per layer of soil enabling the testing of 3 different soil layers. Neoprene rubber pads attached to the face plates with the TDR probes acted as a rubber septum to ensure no leakage of fluid through the holes on this face. A nozzle spray was utilized to spread water on the surface of the soil layer, and the flow rate could be adjusted externally. The outflow was collected by utilizing a reservoir that doubled up as a recycling container. The flux through the sample was monitored by determining the water level in this reservoir. This was achieved by the use of a pressure transducer at the bottom of the reservoir. To ensure that a steady state had been achieved, the readings from the transducer were monitored to ensure little to no change. Additionally the water content readings from the TDR probes were also monitored to determine that no change was occurring. A camera was also employed as a secondary visual check of the water level in the reservoir. A schematic of the experimental setup used in this study is shown in Figure 1 below. 


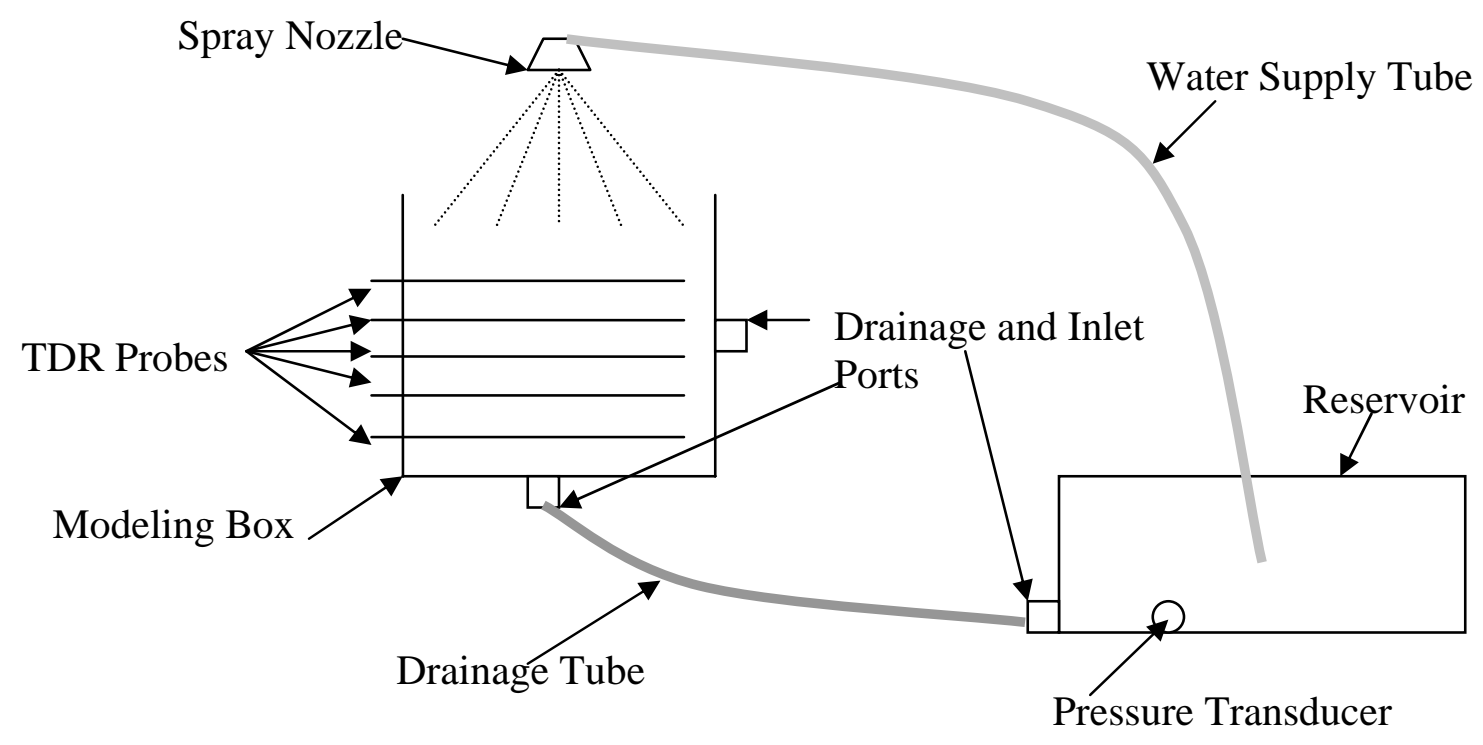

Figure 1. Schematic of Experimental Layout

Initially three different lengths $2,3.5$, and 5 inches of TDR probes were considered to be utilized, however it was determined that the shorter probes did not give reliable water content readings and were therefore replaced with additional 5 inch probes that seem to work very well. Figure 2 shows a digital image of the setup which includes the modeling box, TDR probes, and the reservoir.

\section{MATERIALS}

The porous materials used in the tests consisted of four different glass beads as the porous media to be used in the modeling box. The physical properties of the glass beads are presented in Table 1 below:

Table 1. Physical Properties of Glass Beads

$\begin{array}{lllll}\text { Designation } & \begin{array}{l}\text { Size Range } \\ (\mathrm{mm})\end{array} & \text { Size Range (in) } & \begin{array}{l}\text { Bulk Density } \\ \left(\mathrm{g} / \mathrm{cm}^{3}\right)\end{array} & \mathrm{K}_{\text {sat }}(\mathrm{cm} / \mathrm{sec}) \\ \text { P0170 } & 0.43-0.30 & 0.016-0.012 & 1.57 & 0.12 \\ \text { P0280 } & 0.71-0.50 & 0.028-0.020 & 1.55 & 0.11 \\ \text { A100 } & 1.20-0.80 & 0.047-0.033 & 1.52 & 0.27 \\ \text { A240 } & 2.80-2.00 & 0.111-0.079 & 1.58 & 0.83\end{array}$


Lehigh Centrifuge: Figure 2 shown below is a picture of the Lehigh Centrifuge that was used in the first phase of this study. The Centrifuge is a SCHAEITZ type G4-E with a payload of $50 \mathrm{lb}$ $(22.5 \mathrm{Kg})$. The centrifuge arm has a nominal radius of 26 inches and the radius to the bottom of the box is 33.5 inches $(0.85 \mathrm{~m})$. The centrifuge is capable of an acceleration range of 0 to $100 \mathrm{G}$ and has a capacity of $5000 \mathrm{G}$-pounds.

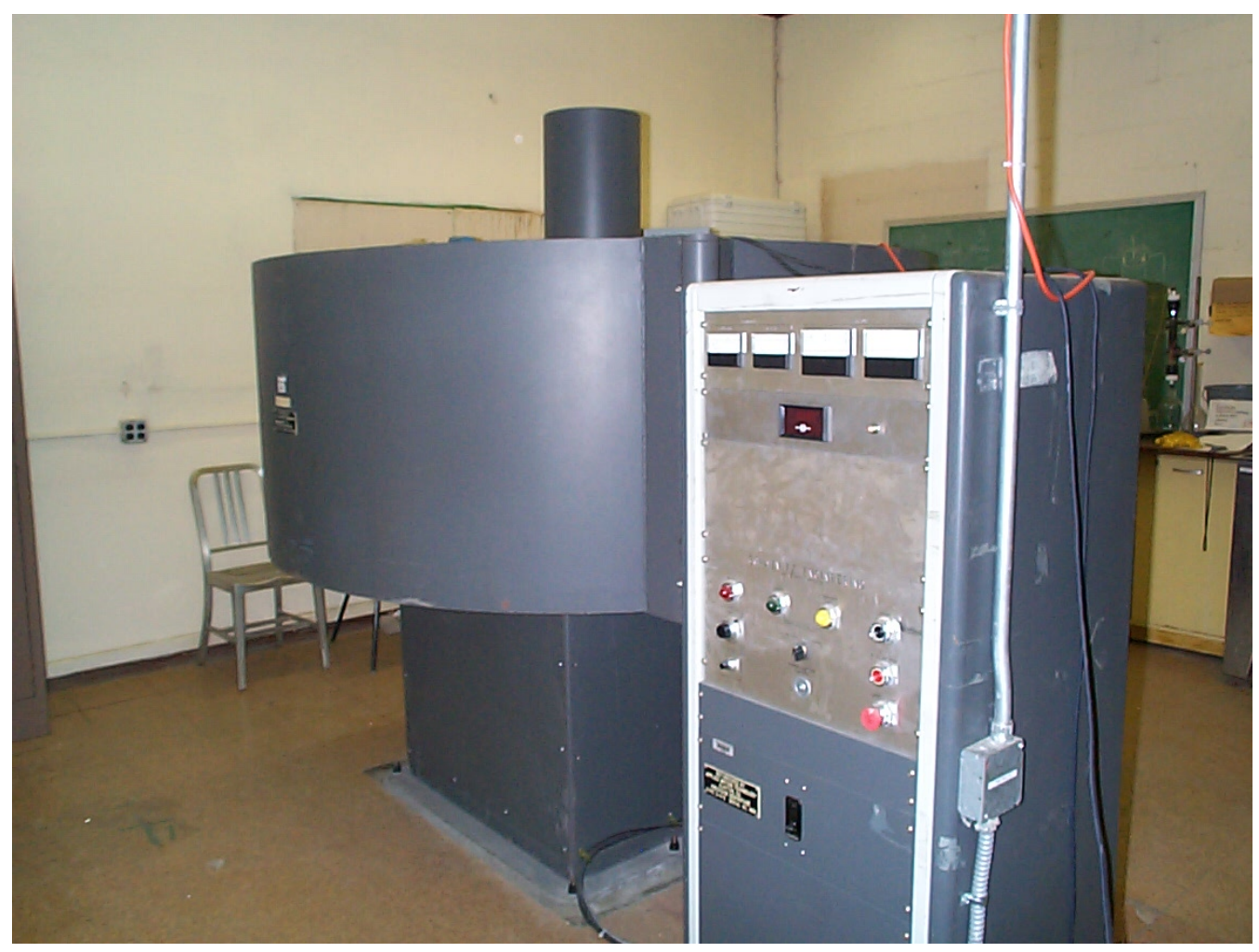

Figure 2. Lehigh Centrifuge and Control Console

\section{METHODS AND PROCEDURES}

Probe Calibration: Calibration of the probes involved immersing the probes in glass beads at different volumetric water contents. Since all the glass beads are made of similar materials, the glass beads A240 were the porous material of choice. At the different water contents a determination of the ratio of an apparent length over actual probe length based on dielectric constants of water and the glass beads enabled a correlation between the dielectric constant and volumetric water content.

Water Characteristic Curve Determination: Water characteristic curves for the four different glass beads were determined by plotting the volumetric water contents of specific quantities of glass beads at various rotational velocities. Testing involved measuring a known volume of glass beads in a cup with a porous base and saturating it with water. The cup was weighed 
before addition of water and after the water was added, saturated, and allowed to drain freely in order to determine the initial water content of the glass beads. The setup was then placed in the centrifuge and rotated at a particular velocity until it reached equilibrium. At each rotational velocity a graduated cylinder was used to collect the drained water, and the residual water in the sample was determined. This step was repeated at increased velocities, until no more water could be collected. The volumetric water content at each velocity could then be calculated.

Determination of Unsaturated Hydraulic Conductivity: A method similar to the UFA method (Conca and Wright., 2000; Nimmo et al.,1987).which establishes steady state flow of water in an unsaturated soil sample in a centrifuge, was used to measure unsaturated hydraulic conductivities for each single material and a layered system as a whole.

\section{RESULTS}

Probe Calibration: Results of testing with the 5 inch and 3.5 inch probes are shown in Figure 3. Based on these results a linear calibration curve was input into the TDR system to give direct water content readings for subsequent tests. The utilization of TDR systems to measure soil water has rapidly gained acceptance as a viable alternative for measuring moisture content in the subsurface (20.Hoekstra and Delaney.,1974; Davis and Annan.,1977; Topp et al.,1980; Whalley.,1993; Zegelin et al.,1989; Ward et al., 1994). Although some TDR systems have been used to determine moisture content without calibration between soil types (Reeves and Smith., 1992), in this study it was determined that optimal results were obtained when the system was calibrated for different soil types.
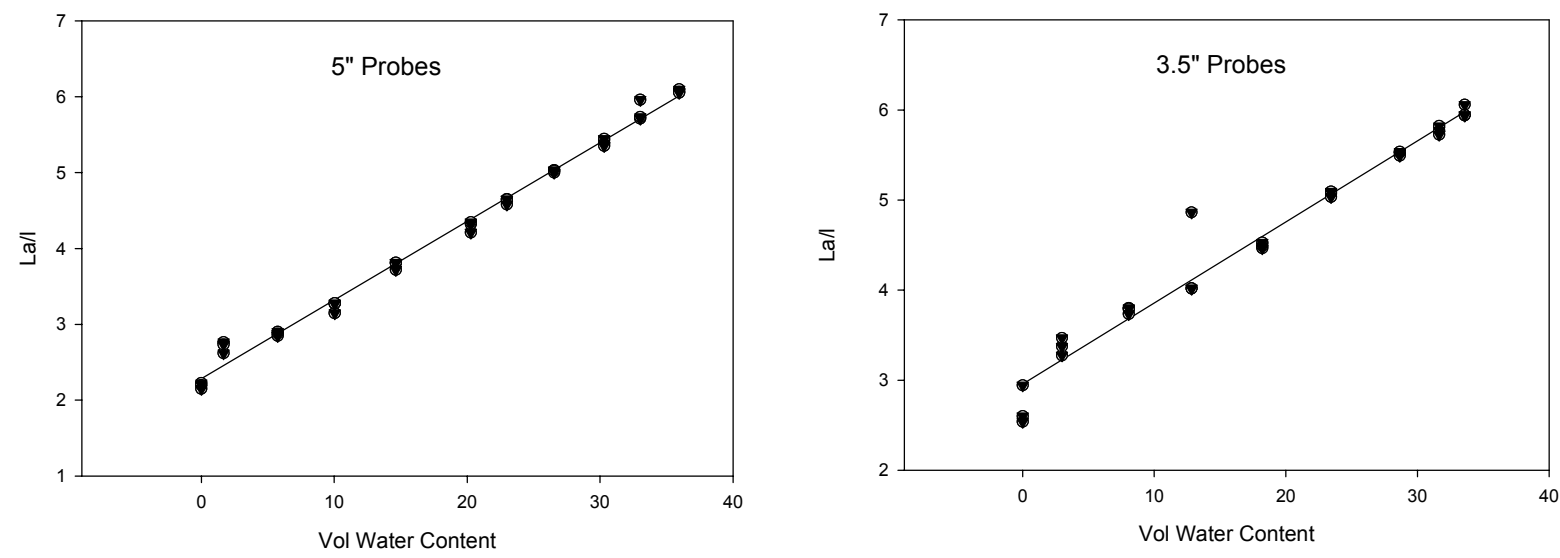

Figure 3. Calibration Curves for TDR Probes. 
Water Characteristic Curve Determination: The results of the water characteristic tests are presented in Figure 4, below which shows the water content and rotational velocity relationship. Figure 5 illustrates Figure 4 as a water characteristic curve plotted with log-scale, and compared with results obtained from the Van Genuchten Model.

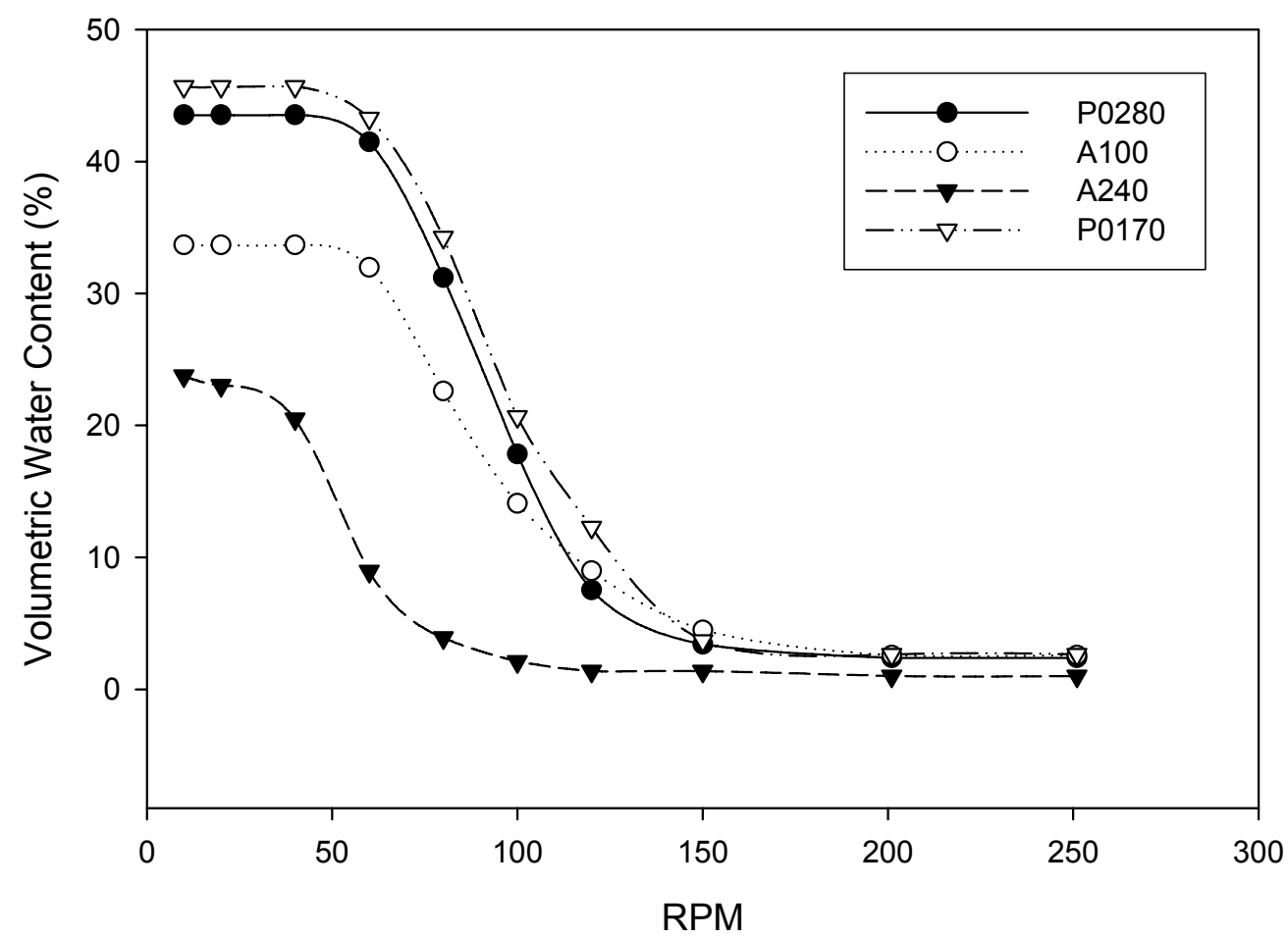

Figure 4. Volumetric Water Content and Rotational Velocity Relationships.

The steady state centrifuge test methods for unsaturated flow characteristics such as UFA, required low inflow rates. Uniform volumetric water contents were achieved under each pair of applied inflow rates and centrifuge speeds. The corresponding unsaturated hydraulic conductivity for this pair was obtained using methods similar to the UFA method.

Verification of Steady State Centrifuge Method: The applied inflow rates were based on the expected range of the hydraulic conductivity of the sample at a given centrifuge rotational speed. The model estimate was based on Van Genuchten modeling although Brook and Corey models could also have been utilized. The model parameters shown in Table 2 were obtained using a program (RECT) developed at US Salinity lab, USDA, by van Genuchten, Simunek, Elij and Sejna. The required parameters for this model as stated above were the soil water retention curve and the saturated hydraulic conductivity. The experimental hydraulic conductivity results versus the sample volumetric water content are shown in Figure 6 and are compared to the theoretical values obtained from RECT. Utilizing an input flow flux of approximately 10 times the saturated hydraulic conductivity $(\mathrm{Q}=10 \mathrm{Ks})$, and spinning the centrifuge at 10G, a saturated steady state flow with a water content approximated to the 
saturated water content of the soil was determined with TDR probes. Subsequent increases of the $\mathrm{G}$ force to $20 \mathrm{G}, 40 \mathrm{G}$, and $60 \mathrm{G}$ corresponding to hydraulic conductivities approximated as $\mathrm{Ks} / 2, \mathrm{Ks} / 4$ and $\mathrm{Ks} / 6$ enabled the determination of steady state flow water contents without having to stop the centrifuge. To measure drier water contents, the inflow flux was adjusted to approximate Ks, and the procedure previously described was then repeated at 10G, 20G, 40G, and 60G, corresponding to hydraulic conductivities approximated as $\mathrm{Ks} / 10, \mathrm{Ks} / 20$, $\mathrm{Ks} / 40$, and $\mathrm{Ks} / 60$. At steady state the water content was then determined for each case. In all the testing scenarios a good fit was noticed between the calculated (theoretical) values and those determined experimentally. Additionally as would be expected the hydraulic conductivity in each case decreased with decreasing water content. Due to the limiting rotational $G$ force, and a limiting minimum input flux that ensured full coverage of the sample, experimental $\mathrm{K}$ determinations below $10 \%$ volumetric water content was not possible. Additional testing with a centrifuge capable of achieving higher $\mathrm{G}$ values will enable the determination of lower volumetric water contents. These results validate the use of the proposed method.

Table 2. Model Parameters for Program RECT that Fit the Water Characteristic Curves Obtained Experimentally

$\begin{array}{cccccc} & \text { Or } & \theta s & \alpha & \mathrm{n} & \mathrm{M} \\ \mathrm{P} 0170 & 1.42 & 45.63 & 0.03449 & 3.45324 & 0.6269 \\ \text { P0280 } & 1.64 & 43.48 & 0.03662 & 3.93832 & 0.6269 \\ \text { A100 } & 2.01 & 33.89 & 0.03904 & 3.15228 & 0.6269 \\ \text { A240 } & 1.08 & 23.45 & 0.10349 & 3.25029 & 0.69233\end{array}$

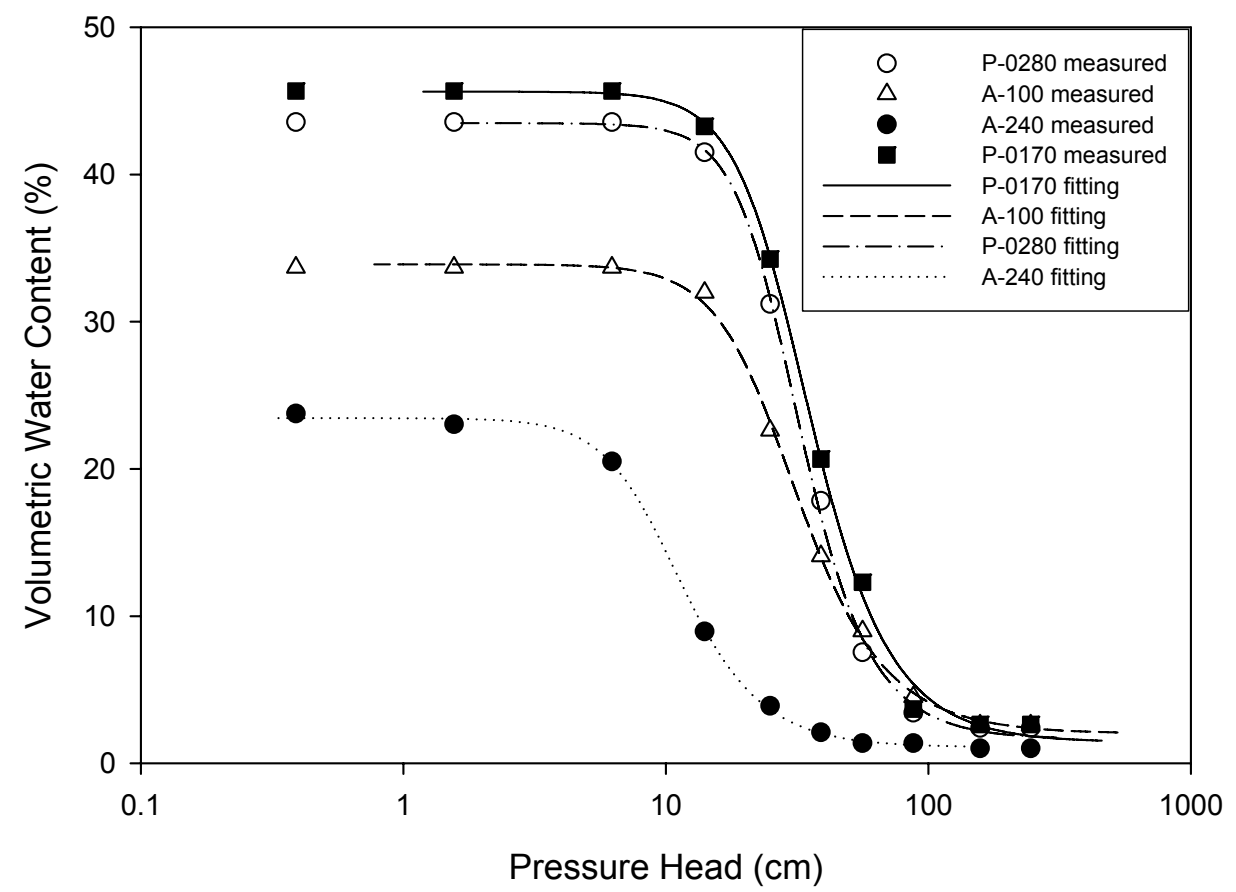

Figure 5. Water Characteristic Curve Results Fitted to Van Genuchten Model. 

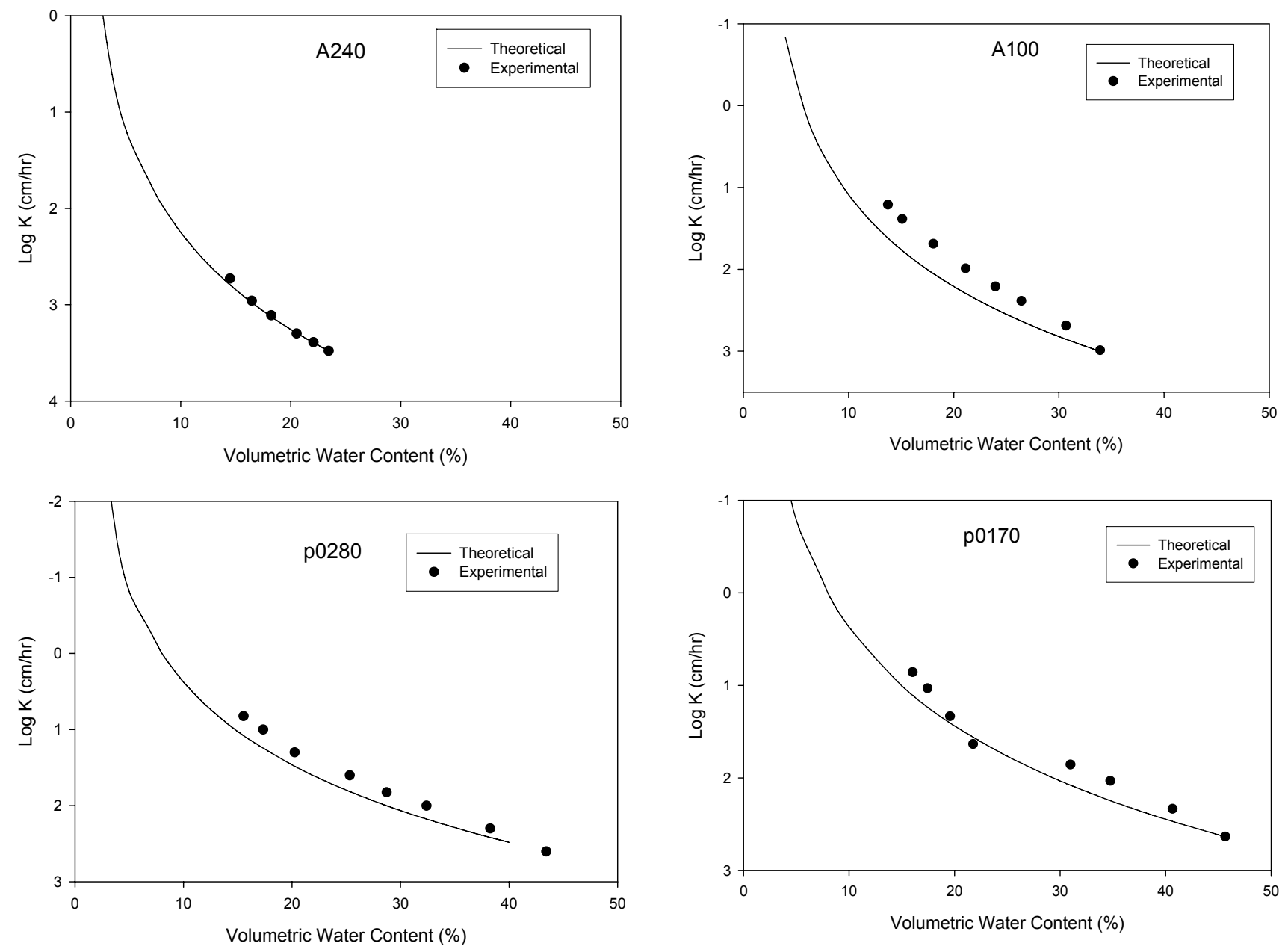

Figure 6. Water Content vs. Hydraulic Conductivity.

One of the tasks in this study was to compare the geotechnical centrifuge used to an Unsaturated Flow Apparatus or UFA ${ }^{\mathrm{TM}}$. Glass bead samples designated as P0170 were sent to UFA Ventures Inc. in Washington State for analysis. Figure 7 plots the unsaturated water content versus the hydraulic conductivity for the sample analyzed with the UFA and the Lehigh geotechnical centrifuge, and from this plot it can be shown that both methods are in agreement in terms of the data obtained at the less saturated end but as the water content increases we notice a very sharp increase to the saturated hydraulic conductivity whereas the results form the Lehigh centrifuge show a much smoother transition. Figure 8 plots the Water Characteristic Curves from the UFA method and the Lehigh geotechnical centrifuge. The UFA method is more suitable for testing at higher pressures in order to obtain the drier end of the Water Characteristic Curve while the geotechnical centrifuge appears to be more suitable for the more 


\section{DE-FG07-02ER63512}

saturated portion of the curve. Figure 8 shows that plotting the curves together actually give a more complete picture of the water characteristic curve.

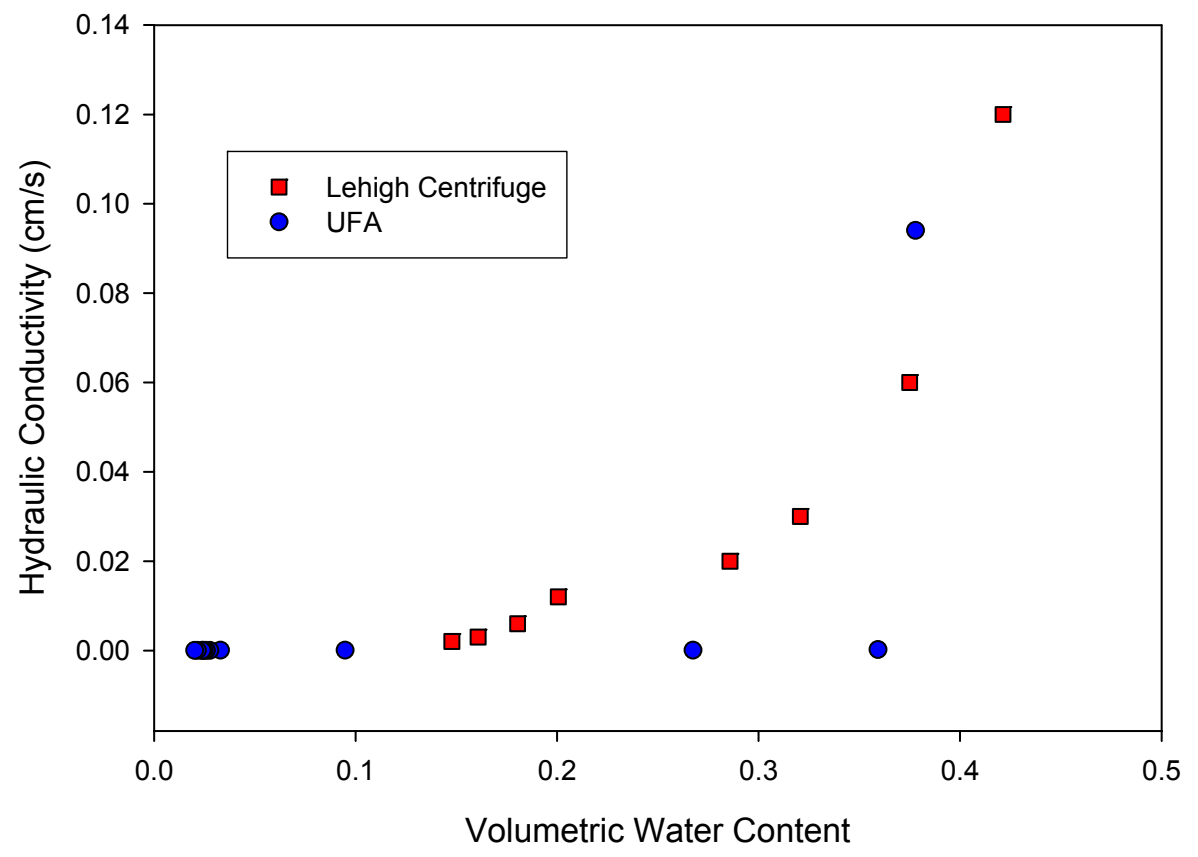

Figure 7. Volumetric Water Content vs. Hydraulic Conductivity for UFA and Geotechnical Centrifuge. 


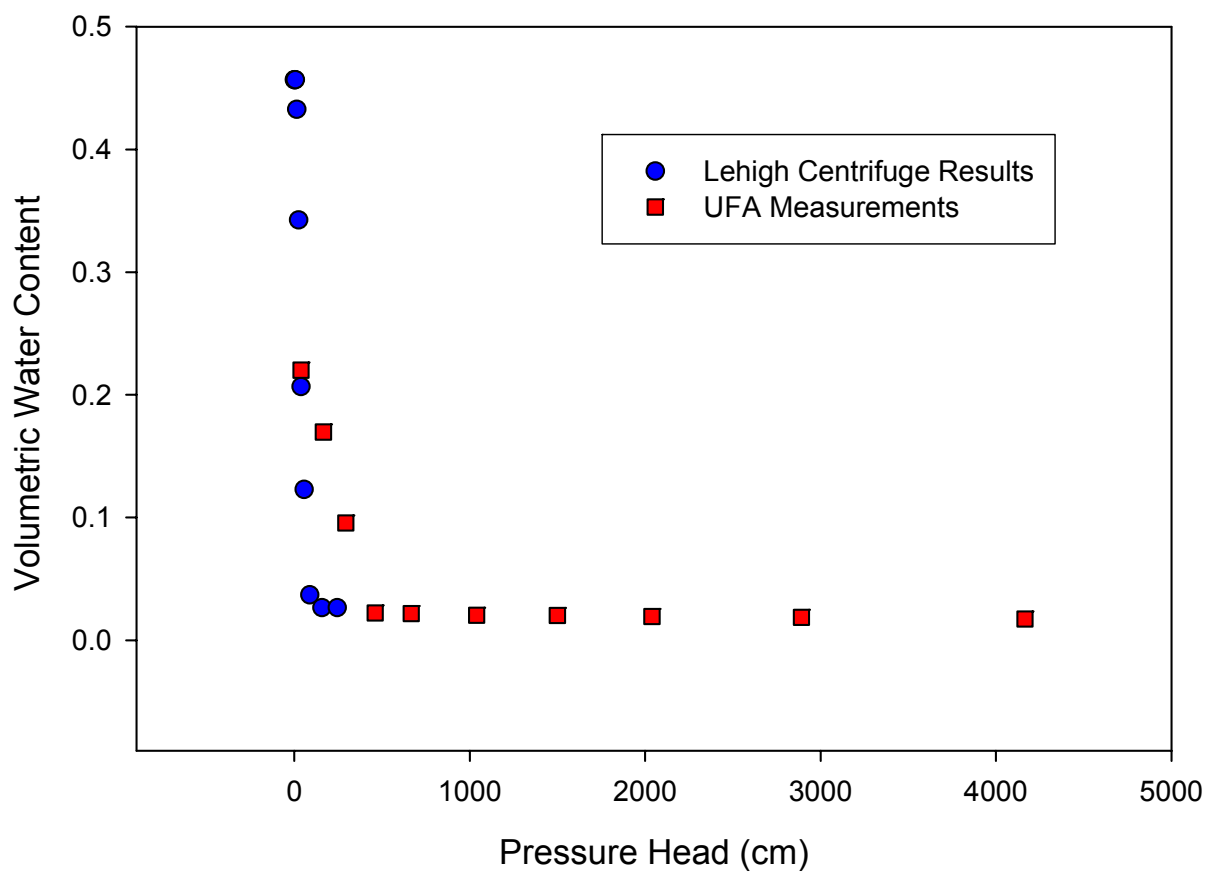

Figure 8. Water Characteristic Curves for UFA and Geotechnical Centrifuge.

Unsaturated Hydraulic Conductivity on a Layered System: Three different sized glass beads were layered and the unsaturated hydraulic conductivity through this system was determined using the method previously described. The glass beads utilized were the A240, A100, and P0280. The glass beads designated P0170 were not used in the system since based on earlier analysis it was determined that its hydraulic properties were similar to those of P0280 as shown in Figure 4. The system was set up such that the finest glass beads were on the bottom, and the largest on top. Following horizontal testing the system was rotated 90 degrees and then retested such that flow was now laterally across the layers. Figure 9 depicts the two setup configurations previously discussed. Figure 10 and 11 are plots of the results obtained showing the relationship between the unsaturated hydraulic conductivity and water content in the horizontal and vertical system respectively. 
Horizontal Layers

\begin{tabular}{|c|c|}
\hline A240 & O TDR3 \\
\hline A100 & O TDR2 \\
\hline P280 & \\
\hline & \\
\hline
\end{tabular}

Vertical Layers

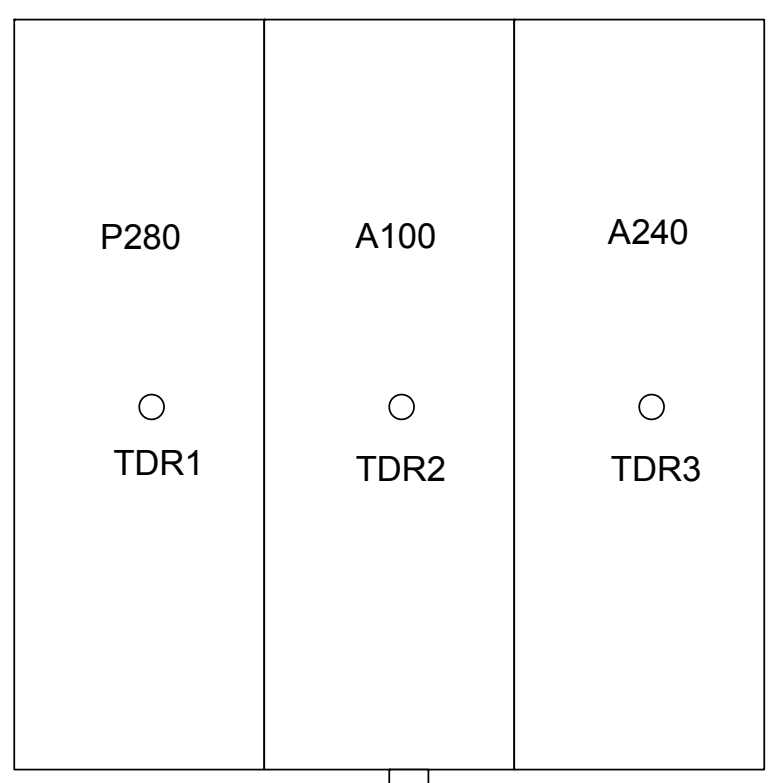

Figure 9. Schematic of Layered System Setup.

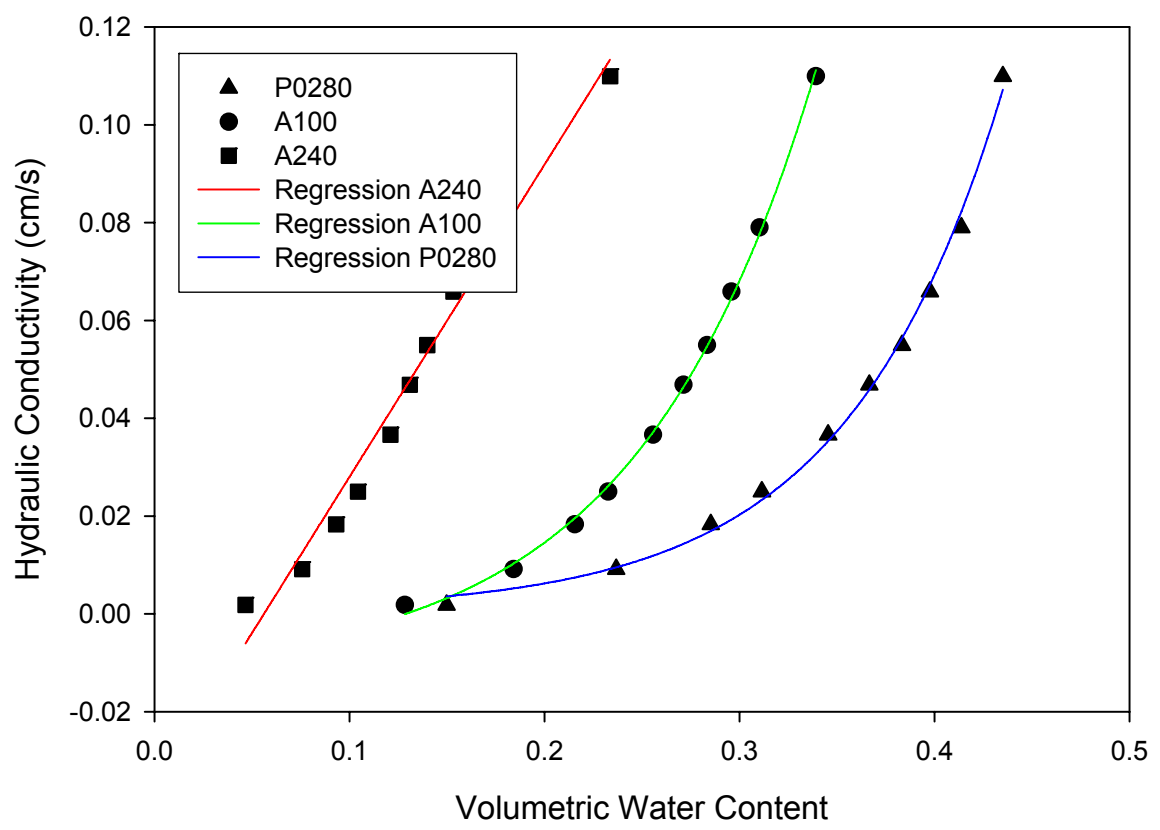

Figure 10. Water Content vs. Hydraulic Conductivity for Horizontal System. 


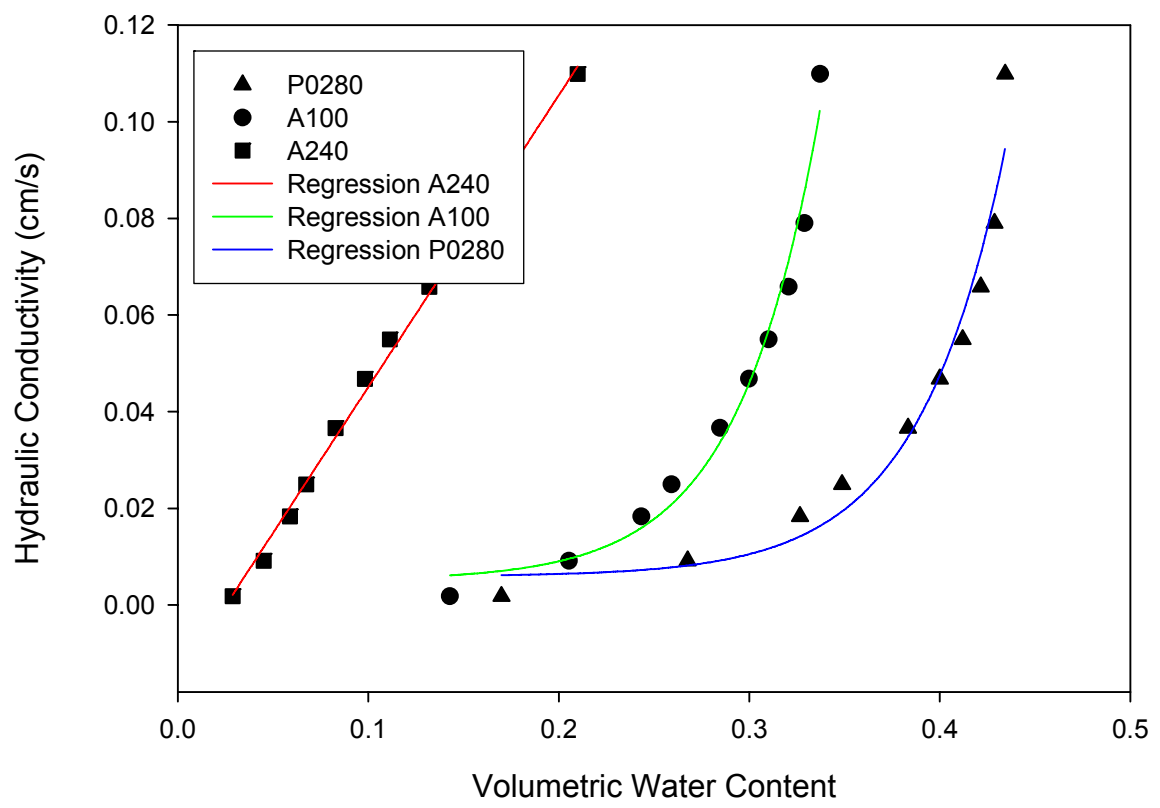

Figure 11. Water Content vs. Hydraulic Conductivity for Vertical System.

In both systems the largest media A240 showed a linear relationship between the hydraulic conductivity and water content, whereas the smaller sized media both exhibited exponential growth relationships. The equations obtained from a regression analysis are shown in Table 3.

Table 3. Equations Describing Hydraulic Conductivity and Volumetric Water Content in Layered Systems

Media and

System

A240 Horizontal

A240 Vertical

A100 Horizontal

A100 Vertical

P0280 Horizontal

P0280 Vertical
Equation Type

Linear

Linear

Exponential Growth

Exponential Growth

Exponential Growth

Exponential Growth
Equation

$$
y=-0.0359+0.0052 x
$$$$
y=-0.0153+0.6039 x
$$$$
y=-0.0123+0.0003 e^{10.9626 x}
$$$$
y=0.0051+3.3042 \times 10^{-5} e^{23.3819 x}
$$$$
y=0.0006+5.0 \times 10^{-4} e^{12.5161 x}
$$$$
y=0.0059+6.266 \times 10^{-6} e^{22.014 x}
$$

$\mathbf{R}^{2}$

0.972

$y=$ hydraulic conductivity, $x=$ volumetric water content

Since we want to consider the layered system as a bulk system, we need to take the hydraulic conductivity of the system and compare it to the average water content for the system. Figure 12 is a plot of the average volumetric water content versus the hydraulic conductivity of the system. 


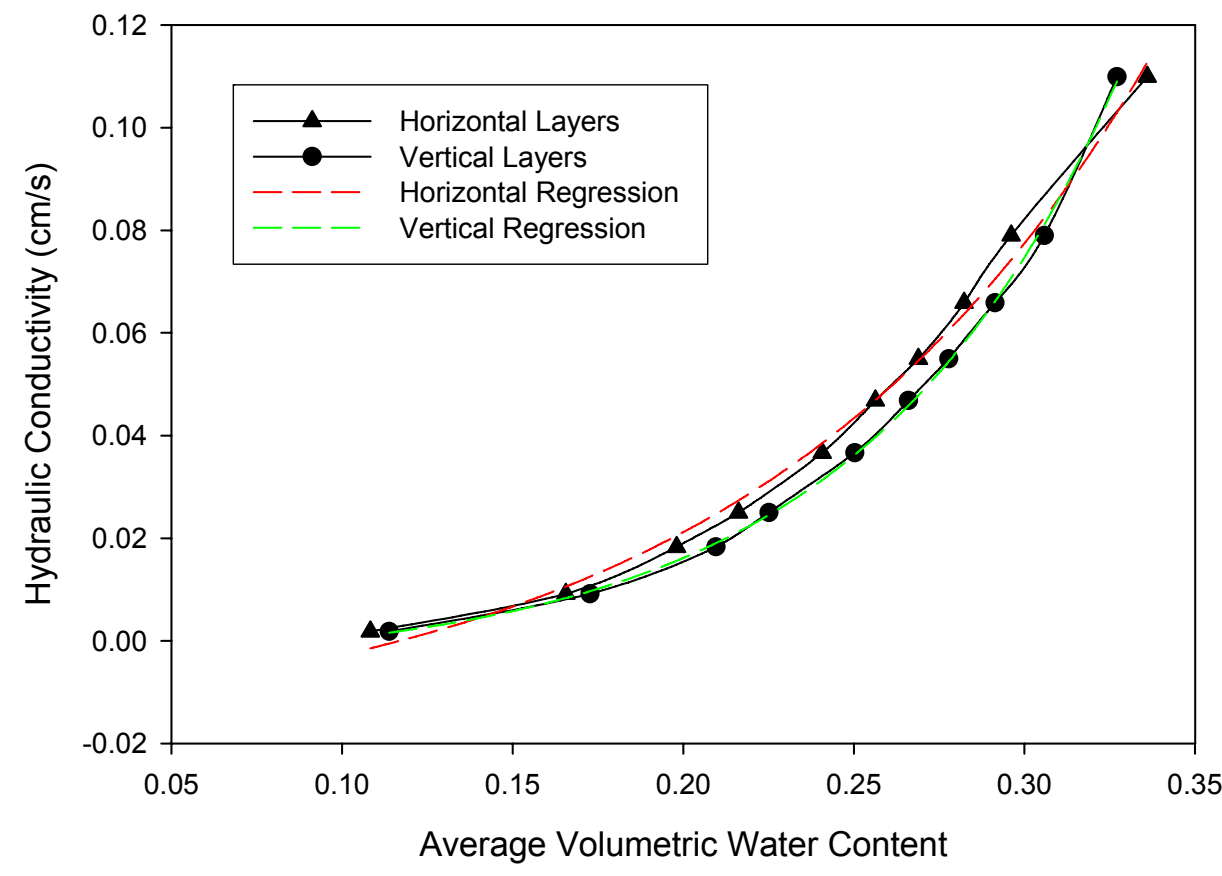

Figure 12. Average Volumetric Water Content vs. Hydraulic Conductivity for Vertical and Horizontal Systems

The degree of anisotropy can be represented by an anisotropic coefficient $A$ defined by the following relationship:

$$
A=\frac{K_{h}}{K_{v}}
$$

A nonlinear regression of both the horizontal and vertical system using exponential growth showed that the plots could be described by the following equations where the hydraulic conductivity is represented by $\mathrm{y}$ and the volumetric water content by $\mathrm{x}$ :

$$
\begin{array}{lll}
\text { Horizontal System } & y=-2.047 \times 10^{-2}+7.536 \times 10^{-3} e^{8.547 x} & \mathrm{R}^{2}=0.993 \\
\text { Vertical System } & y=-5.296 \times 10^{-3}+1.541 \times 10^{-3} e^{13.17 x} & \mathrm{R}^{2}=0.999
\end{array}
$$

Using the preceding equations a plot of the Anisotropy Coefficient vs. volumetric water content can be obtained as shown in Figure 13. From the plot it appears that within this system anisotropy increases from a dry state, but after a certain amount of saturation within the system the trend is reversed as saturation increases. 


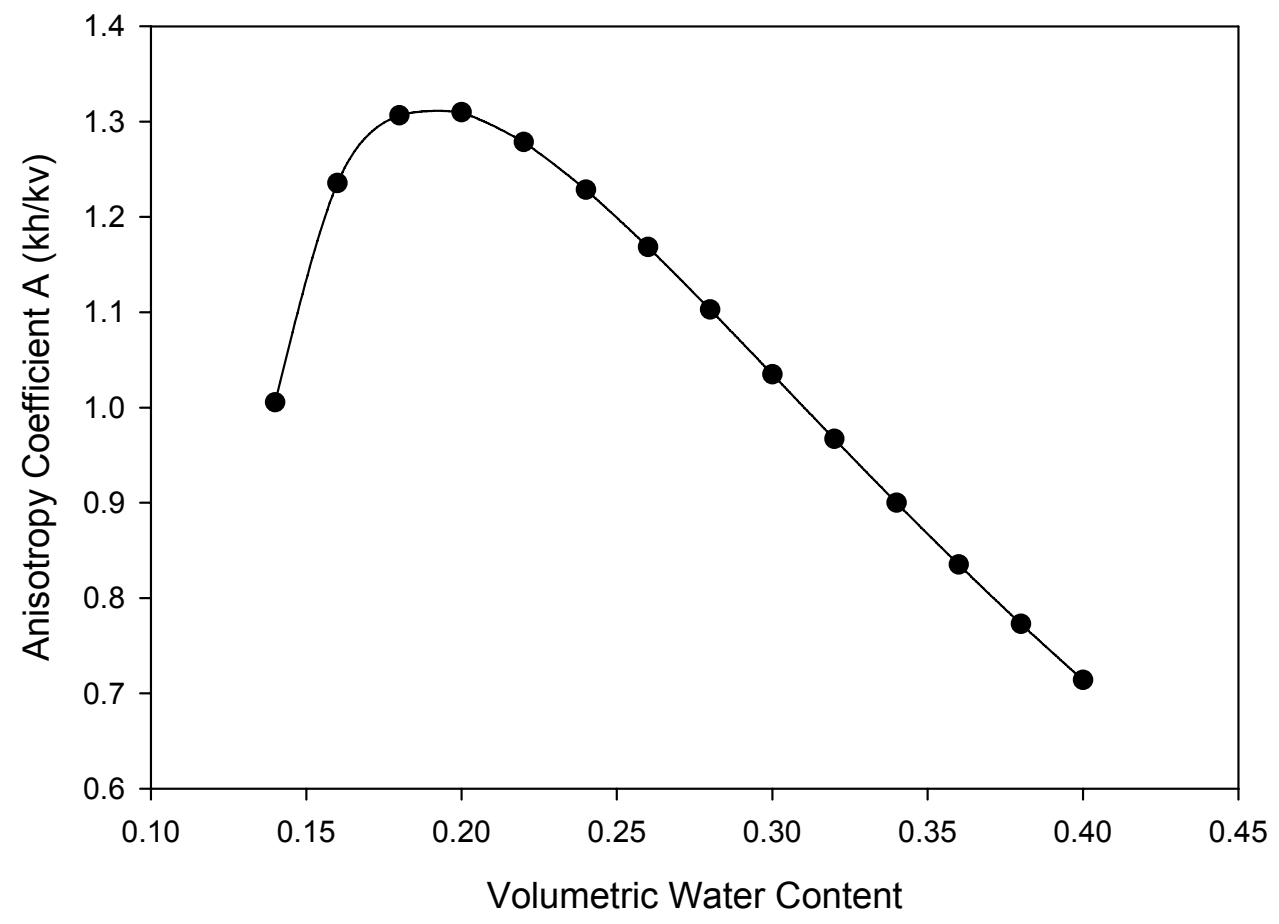

Figure 13. Anisotropy Coefficient vs. Volumetric Water Content for a Layered System.

\section{TESTING AT COLUMBIA UNIVERSITY}

Following the Lehigh Tests it was decided that testing should be done on larger samples, and to accomplish this, a Large Scale 200G Centrifuge located at Columbia University New York and shown in Figure 14 below was used. The centrifuge has a rotating arm with a $2 \mathrm{~m}$ radius, and a strong box whose dimensions are 40 in $\times 25$ in $\times 15$ in $(100 \mathrm{~cm} \times 60 \mathrm{~cm} \times 37.5 \mathrm{~cm})$, and is capable of accepting up to $1000 \mathrm{~kg}$ at $100 \mathrm{G}$ and $550 \mathrm{~kg}$ at $200 \mathrm{G}$. 


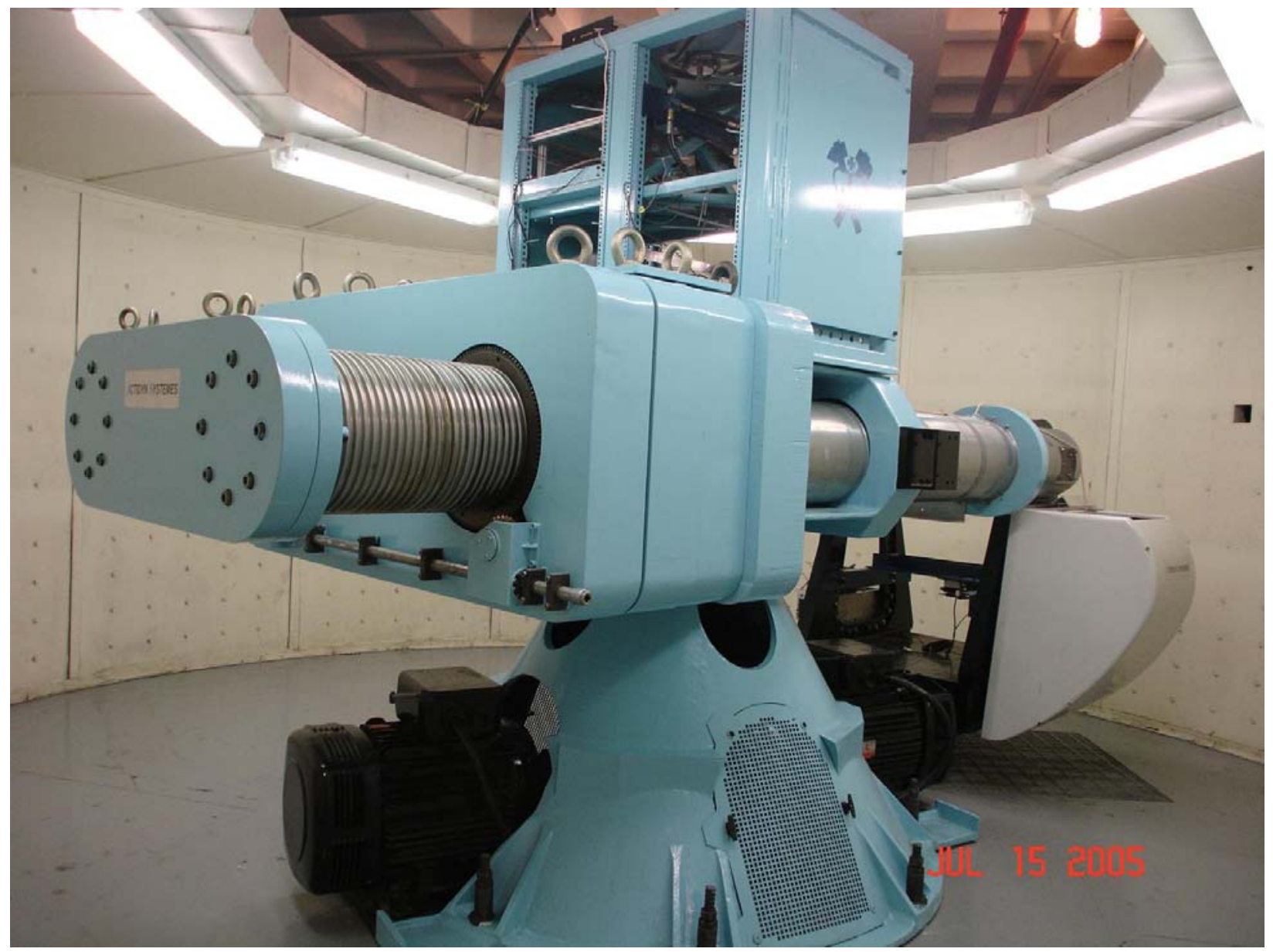

Figure 14. Columbia University Centrifuge

The experimental setup used in this phase of the study was similar to the one used in the initial phase of the study and shown in Figure 1 with the only major difference being a bigger modeling box measuring 12 in $\times 12$ in $\times 12$ in. The other major difference is that the probes used here were 12 inch probes as opposed to the shorter probes previously used. Figure 15 shows the setup of the modeling box with attached probes, placed inside the strongbox within the centrifuge. 


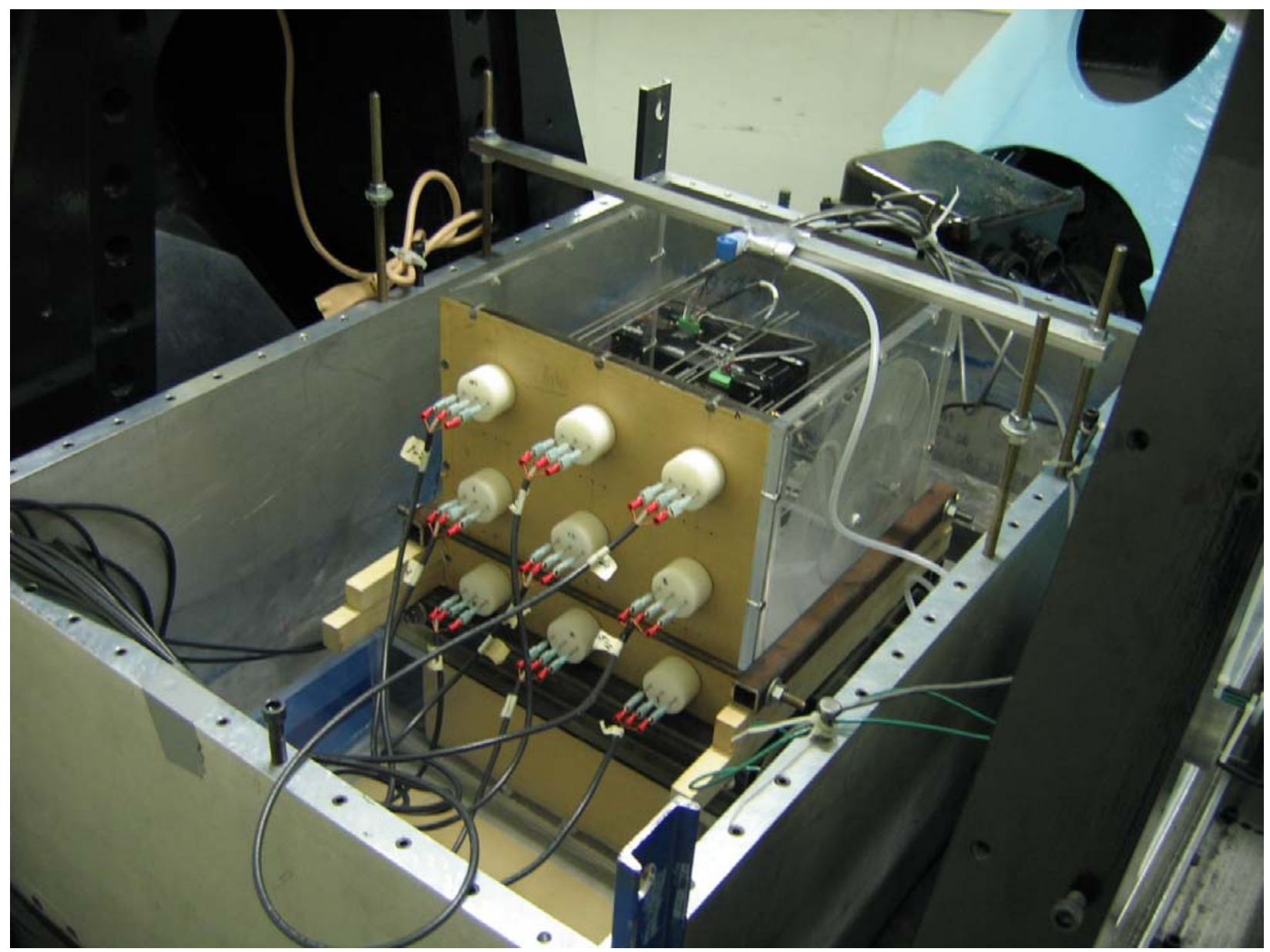

Figure 15. Modeling Box Setup in Columbia Centrifuge.

Mica Testing: Since It is reasonable to expect that the degree of anisotropy in permeability is affected by particle shape and alignment, and other researchers (Stewart et al., 2006) have stated that "in random packs more oblate particles and higher degrees of particle alignment lead to reduced permeability perpendicular to the direction of particle alignment compared to the direction parallel to particle alignment", attempts were made to use mica particles to investigate this. Mica is a group of sheet silicate minerals that have highly perfect basal cleavage that generally makes them flat. The particular Mica chosen here was a Muscovite Mica and during hydration it was noticed that there was significant swelling. After compaction and reduction of the water content it was discovered that upon desiccation the Mica cracked as shown in Figure 16 , and therefore could not be used in this study. 


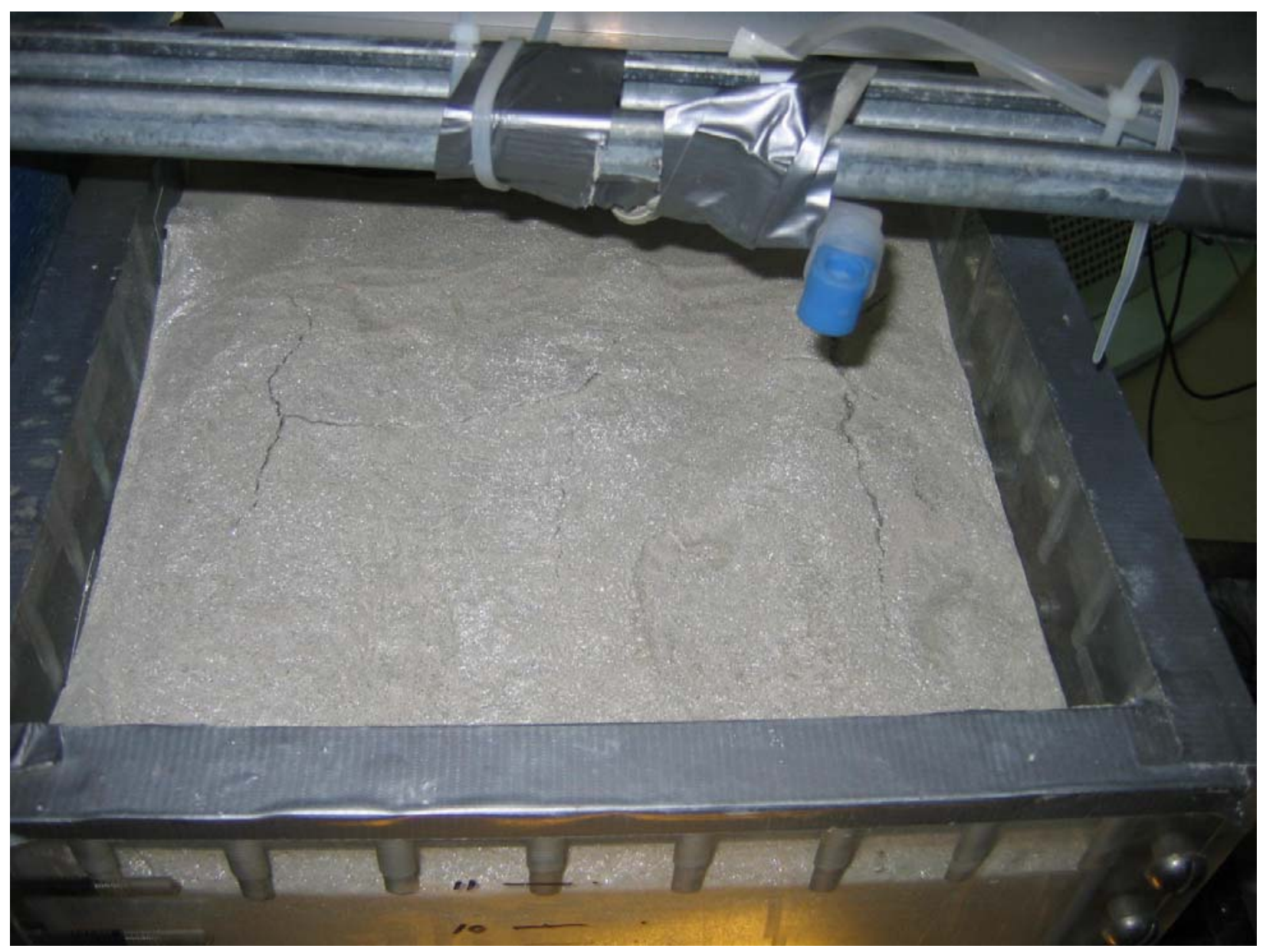

Figure 16. Modeling Box showing Mica Cracks.

Glass Beads Testing: Additional layered tests similar to those performed at Lehigh were performed at Columbia. A parameter we wanted to consider related to pore connectivity and tortuoisity. The hydraulic conductivity or permeability of a porous media is determined by the pore network of the media. The pore network of a porous media can be characterized by four aspects: pore size, pore geometry, pore tortuosity and pore connectivity. Current statistical models for hydraulic conductivity and permeability are based on the distribution of the pore sizes and use matching parameters to incorporate the effects of pore tortuosity and connectivity into the models. Hoffmann-Riem et al., (1999) use a lumped parameter $L$ to account for pore connectivity and tortuoisity. Zhang et al., (2003) call this lumped parameter the connectivitytortuosity coefficient. In van Genuchtens model this coefficient is treated as a constant with a value of 0.5. However Mualem (1976) states that $L$ varies and he determined it to be an optimal value from a data set of 45 disturbed and undisturbed samples. (Zhang et al., 2003). In this study we measured the hydraulic conductivity corresponding to various water contents for both a horizontal and vertical layer system. We used these measured values to fit the Van- 
Genuchten-Mualem model in order to determine the tortuosity connectivity coefficient, and assumed that the water characteristics curve did not change with $\mathrm{G}$ level. Figure 17 is a plot of the Relative Hydraulic Conductivity $\mathrm{K}_{\mathrm{r}}$ (A ratio of the hydraulic conductivity to the saturated hydraulic conductivity) against the $G$ level. In the plot we notice that $K_{r}$ decreases with increasing $G$ which indicates that as the soil gets drier the hydraulic conductivity decreases.

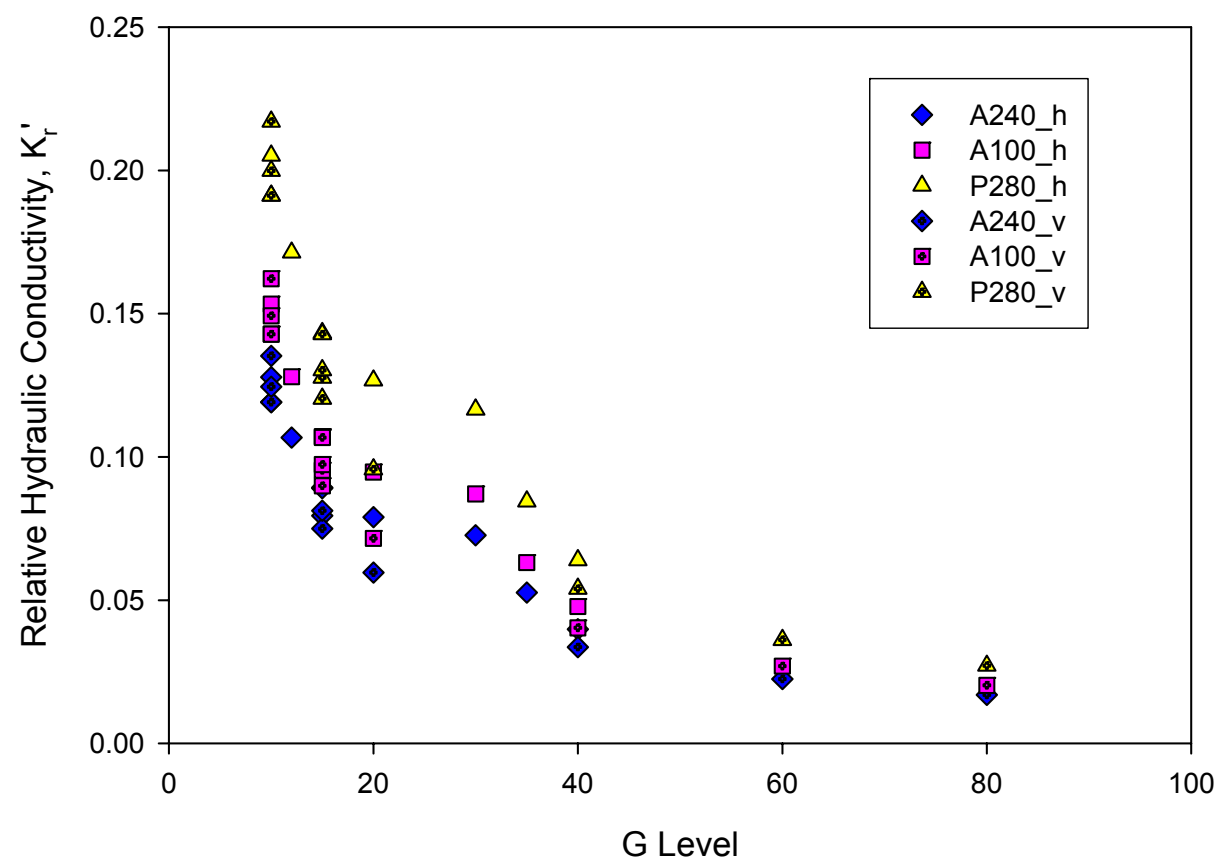

Figure 17. Relative Hydraulic Conductivity $\mathrm{K}_{\mathrm{r}}$ vs. G level.

\section{CONCLUSIONS}

From the experimental results it was also noticed that the the tortuosity and connectivity term $\mathrm{s}_{\mathrm{e}}{ }^{\mathrm{L}}$ in the van Genuchten hydraulic conductivity model (van Genuchten, 1980) changes with the $G$ level. A basic trend is that at higher $G$ values, which results in lower water contents, the value of $S_{e}{ }^{L}$ is higher, which may indicate that at higher $G$ levels the tortuosity effect dominate pore size distribution effects as shown in Figure 18 which plots the tortuosity connectivity coefficient against the $\mathrm{G}$ level. The $\mathrm{G}$ force effect on tortuosity can be attributed to the shifting dominance between the $G$ force and the suction. When the water content is high, the suction is low, and $G$ force dominates forcing the water through a less tortuous path. When the water content is low, suction dominates and the water tends to spread horizontally and the flow path is more tortuous. In our tests, higher $\mathrm{G}$ levels correspond to lower water contents resulting in greater tortuosity. 


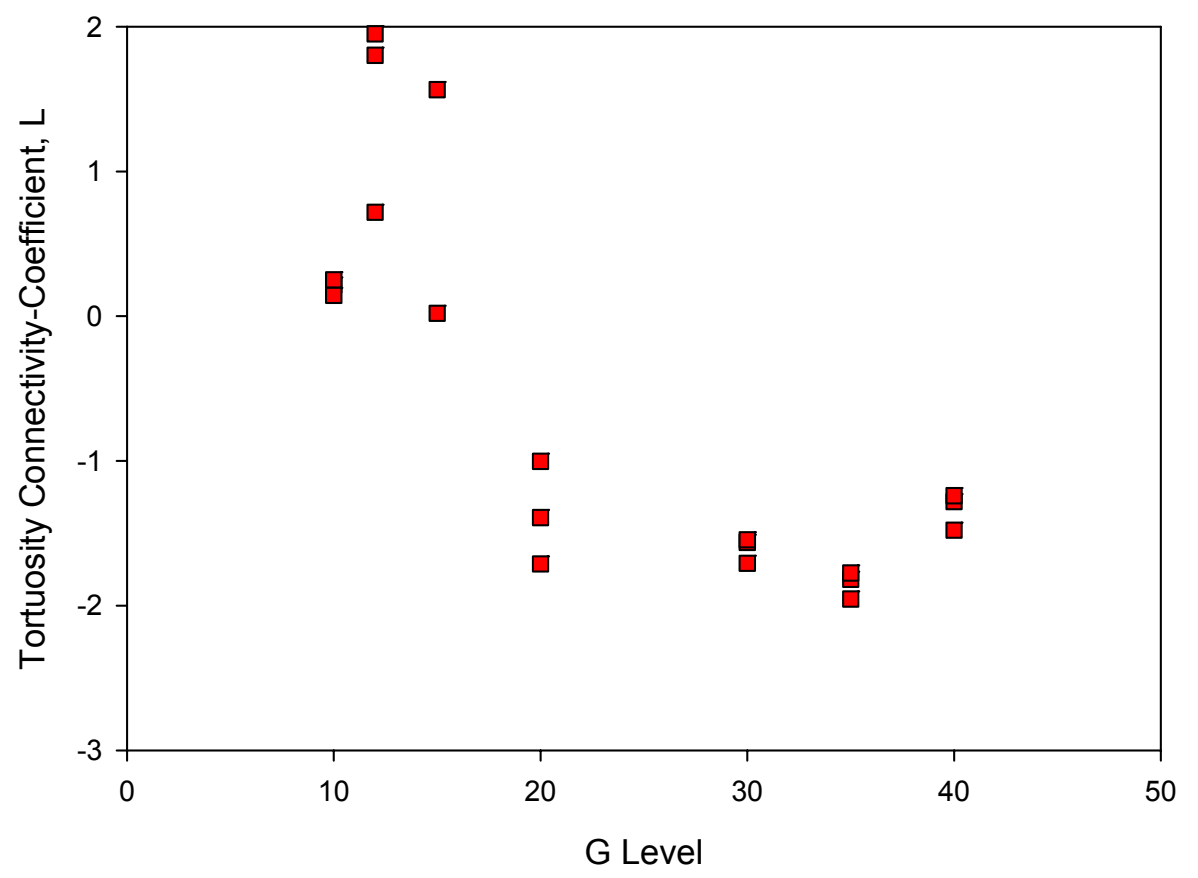

Figure 18. Tortuosity Connectivity Coefficient vs. G level.

Our results also indicated that the value of the tortuosity connectivity coefficient $L$ varied over a wide range and is a function of the effective water content, $\mathrm{s}_{\mathrm{e}}$ as shown in Figures 19 and 20 for the horizontal and vertical layer systems respectively. Both plots show that at higher saturation values $L$ has a positive value, while at lower saturation values, it becomes negative. The turning point from positive to negative seems to be a function of the soil type, such that finer the soil the higher the turning point $\mathrm{s}_{\mathrm{e}}$ value. Likewise orientation also seems to affect the point at which $L$ changes from negative to positive. 


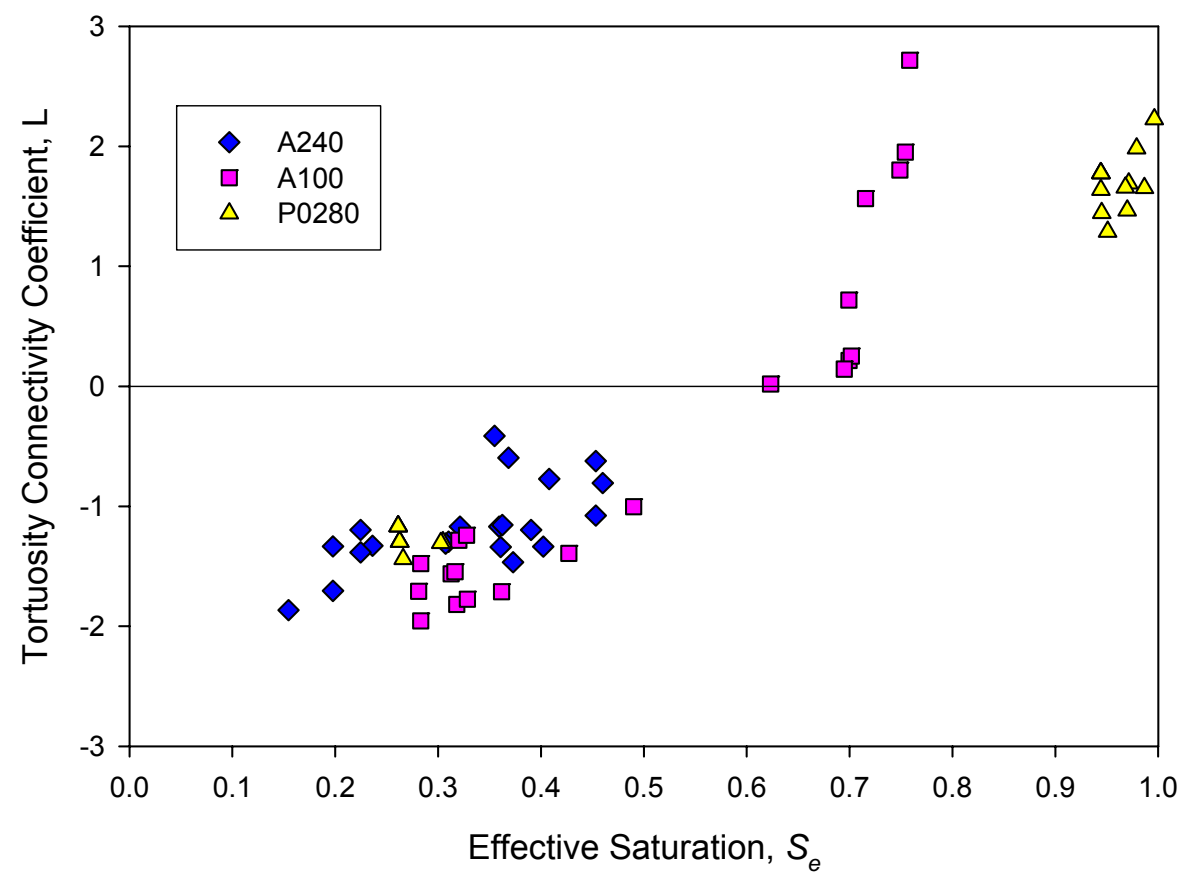

Figure 19. Tortuosity Connectivity Coefficient vs. Effective Saturation, $s_{e}$ For Horizontal System

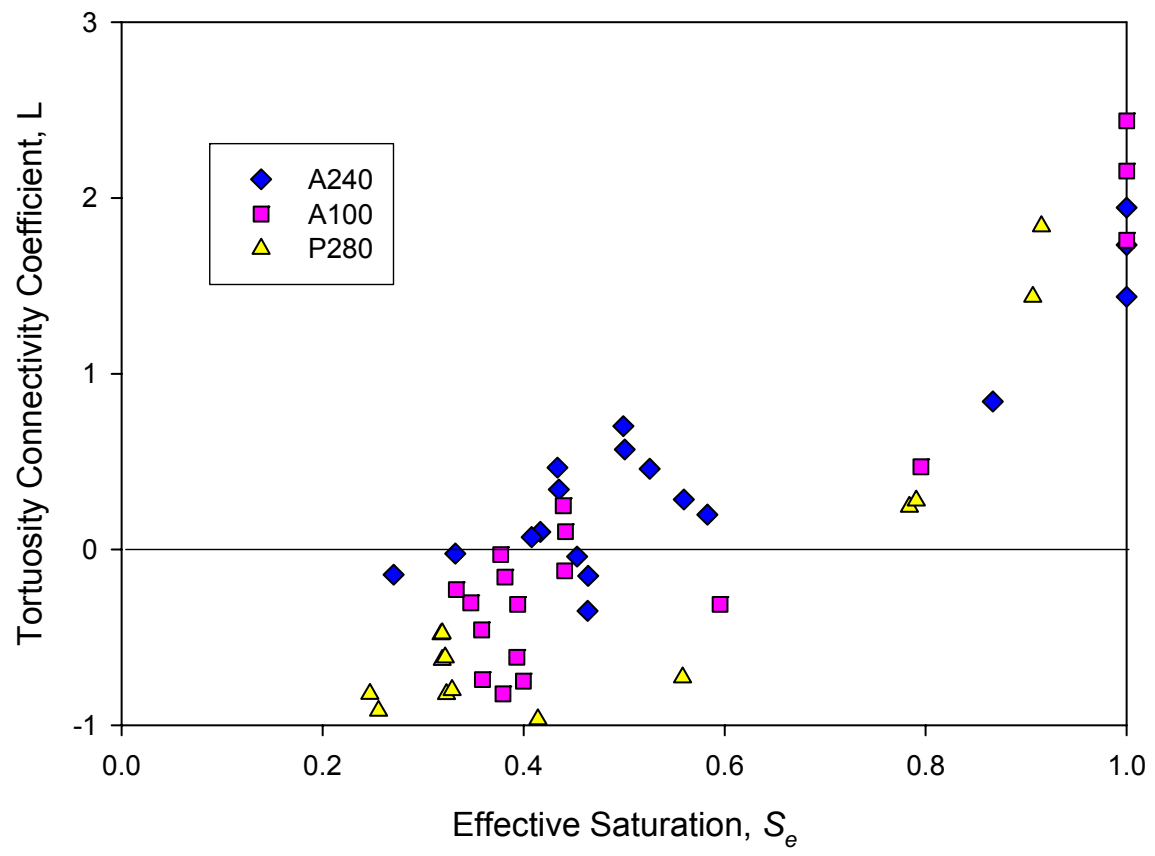

Figure 20. Tortuosity Connectivity Coefficient vs. Effective Saturation, $s_{e}$ For Vertical System 
These results indicate that there may be a scaling law on the tortuosity in the centrifuge tests. This scaling would then affect the scaling of the unsaturated hydraulic conductivity, which will not be $\mathrm{N}$ as traditionally assumed. Alternatively it could also mean that the power function in the van Genuchten hydraulic conductivity model does not completely account for the effects of tortuosity and connectivity.

\section{REFERENCES}

Conca, J.A., and Wright, J.A. (2000). The UFA Method for Characterization of Vadose Zone Behavior. UFA Ventures, Inc., 2000 Logston Blvd, Richland. (available at http://www.ufaventures.com)

Davis, J.L., and Annan, A.P. (1977). Electromagnetic Detection of Soil Moisture: Progress Report I. Can. J. Remote Sens. 3: 76-86

Gee, G.W., and A.L. Ward. (2001). Vadose Zone Transport Field Study: Status Report. PNNL13679, Pacific Northwest National Laboratory, Richland, Washington.

Hoekstra, P., and A. Delaney. (1974). Dielectric properties of soils at UHF and microwave frequencies. J. Geophys. Res. 79:1699-1708.

Hoffmann-Riem, H., van Genuchten, M.Th., and Fluhler, H. (1999). A General Model of the Hydraulic Conductivity of Unsaturated Soils. p. 31-42. In M.Th. van Genuchten et al. (ed.) Proc. Int. Workshop, Characterization And Measurements Of The Hydraulic Properties Of Unsaturated Porous Media, Riverside, CA. 22-24 Oct. 1997.- University of California, Riverside.

Mualem,Y. (1976) .A New Model for Predicting the Hydraulic Conductivity of Unsaturated Porous Media. Water Resour. Res. 12: 513 - 522.

Nimmo, J.R., Rubin, J., and Hammermeister, D.P. (1987). Unsaturated Flow in a Centrifugal Field: Measurement of Hydraulic Conductivity and testing of Darcys Law. Water Resour. Res. 23(1): 124-134.

Reeves, T.L., and Smith, M.A. (1992). Time Domain Reflectometry for Measuring Soil Water Content in Range Surveys. J. Range Manage. 45(4): 412-414

Rouston, R.C., W.H. Price, D.J. Brown, and K.R. Fecht. (1979). High Level Waste Leakage from the 241-T-106 Tank at Hanford. RHO-ST-14. Rockwell Hanford Operations, Richland, Washington.

Stewart, M.L.., Ward, A.L., and Rector, D.R. (2006). A Study of Pore Geometry Effects on Anisotropy in Hydraulic Permeability Using the Lattice-Boltzmann Method. Adv. Wat. Res. 29: $1328-1340$

Topp, G.C., Davies, J.L., and Annan, A.P. (1980). Electromagnetic determination of soil water content: Measurements in coaxial transmission lines. Water Resour. Res. 16:574-582

United States Department of Energy-Grand Junction Projects Office (DOE-GJPO). (1998). Vadose Zone Characterization Project at the Hanford Tank Farms: BX Tank Farm Report, GJO-98-40-TAR (GJPO-HAN-19), Grand Junction, Colorado.

Van Genuchten, M.Th. (1980). A Closed-Form Equation for Predicting the Hydraulic Conductivity of Unsaturated Soils. Soil Sci. Soc. Am. J. 44:892-898. 
Ward, A. L., G. W. Gee, and M. D. White. (1997). A comprehensive analysis of contaminant transport in the vadose zone beneath Tank SX-109. PNNL-11463. Pacific Northwest National Laboratory, Richland, Washington.

Ward, A.L., Kachanoski, R.G., and Elrick, D.E. (1994). Laboratory Measurements of Solute Transport Using Time Domain Reflectometry. Soil Sci. Soc. Am. J. 58: 1031-1039.

Whalley, W.R. (1993). Considerations on the use of time domain reflectometry (TDR) for measuring soil water content. J. Soil Sci. 1:1-9.

White, M.D., M. Oostrom, M. D. Williams. (2001). Initial Assessments for S-SX Field Investigation Report FIR): Simulations of Contaminant Migration with Surface Barriers, PNWD-3111, Pacific Northwest National Laboratory, Richland, Washington.

Zhang, Z.F., Ward, A.L., and Gee, G.W. (2003). A tensorial Conneectivity-Tortuosity Concept to Describe the Unsaturated Hydraulic Properties of Anisotropic Soils. Vad, Zon, J. 2: 313321

Zegelin, S.J., I. White, and D.R. Jenkins. (1989). Improved Field Probes for Soil Water Content and Electrical Conductivity Measurement Using Time Domain Reflectometry. Water Resour. Res. 25:2367-2376.

Patents: None. 
Budget Data (as of 10-13-2006): The approved spending should not change from quarter to quarter. The actual spending should reflect the money actually spent on the project in the corresponding periods.

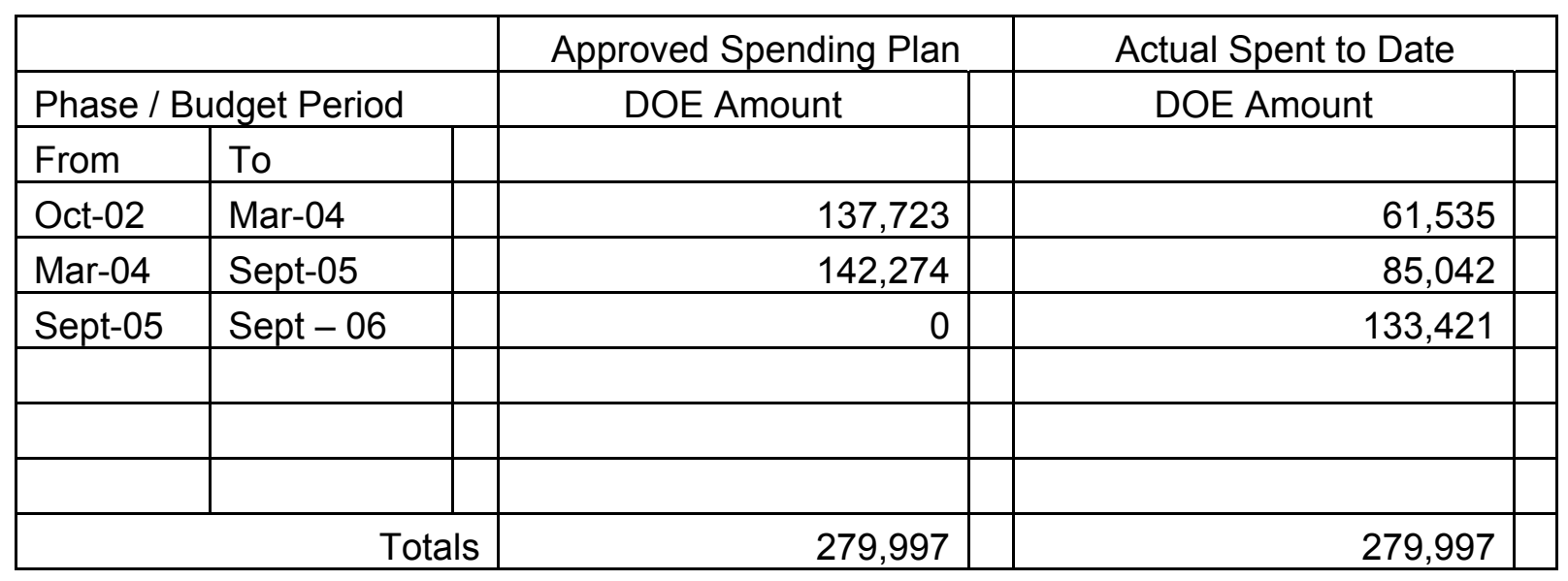

